\title{
Life cycle assessment and circularity indicators
}

\author{
Lucia Rigamonti $^{1}$ (D) Eliana Mancini ${ }^{2}$
}

Received: 18 June 2021 / Accepted: 19 August 2021 / Published online: 7 September 2021

(c) The Author(s) 2021

\begin{abstract}
Purpose In a context where the transition to a circular economy is increasingly required, it is necessary to clarify the relationship between sustainability and circularity. In this commentary we summarise what are circularity indicators and what is LCA (Life Cycle Assessment), and we discuss their potential role in improving circular decision making.

Methods Based on literature, a focus on how circularity indicators and LCA could be used in circular decision making is presented. Moreover, an analysis of recent studies has been carried out to identify the relationship between LCA and circularity indicators.

Results and discussion We can state that no authors have concluded that circularity indicators can be used alone to choose the best option in circular economy projects. This is because the circularity indicators only provide a partial view on the environmental performance of a system. At the same time, it appears that the circularity indicators are easier to communicate, and a high degree of circularity could help to build good relationships with customers and increase reputation among stakeholders, as well as to have an easier access to funding.

Conclusions and recommendations At the end, we propose a procedure to include both the LCA and the circularity measurement in the assessment of circular economy strategies. While still at an early stage of conceptualisation, it gives an idea on how to integrate environmental sustainability aspects into circular economy initiatives.
\end{abstract}

Keywords Circular economy $\cdot$ LCA $\cdot$ Life cycle assessment $\cdot$ Sustainability $\cdot$ Circularity indicator $\cdot$ Assess circularity

\section{Introduction}

Circular economy (CE) is an approach developed due to the need to provide concrete response to implement the concept of sustainable development (Murray et al. 2017; Corona et al. 2019; Saidani et al. 2019) shifting from a linear economy model to a circular one (Ellen MacArthur Foundation 2013). Although CE is considered by different authors a relatively young approach (Murray et al. 2017; Sassanelli et al. 2019), this was first coined and used in 1990 (Pearce and Turner 1990). Currently, several definitions of

Communicated by Matthias Finkbeiner.

Lucia Rigamonti

lucia.rigamonti@polimi.it

1 Civil and Environmental Engineering Department, Politecnico Di Milano, Piazza Leonardo da Vinci 32, 20133 Milano, Italy

2 Department of Economic Studies, Università Degli Studi "G. D’Annunzio", Viale Pindaro 42, 65127 Pescara, Italy
CE could be found in the literature, as observed by some authors (Geissdoerfer et al. 2017; Kirchherr et al. 2017). Such definitions derive from different fields (Korhonen et al. 2018). One of the most cited (Kirchherr et al. 2017, p. 229) describes $C E$ as "an economic system that replaces the 'end-of-life' concept with reducing, alternatively reusing, recycling and recovering materials in production/distribution and consumption processes. It operates at the micro level (products, companies, consumers), meso level (ecoindustrial parks) and macro level (city, region, nation and beyond), with the aim to accomplish sustainable development, thus simultaneously creating environmental quality, economic prosperity and social equity, to the benefit of current and future generations".

The diverse conceptualizations of CE (Kirchherr et al. 2017; Murray et al. 2017) lead to put into practice alternative circularity strategies (Corona et al. 2019). Hence, CE has been considered a sort of umbrella concept that summarized different approaches (Bracquené et al. 2020). For example, $\mathrm{CE}$ is often associated to the 3 or $4 \mathrm{R}$ approach-reduce, reuse, recycle and recover (Kirchherr et al. 2017; Murray 
et al. 2017; Helander et al. 2019)—or to business models circular-oriented. The variety of approaches and strategies depends on the absence of a standardized framework. To deal with this, a group of ISO Standards are currently under development by the Technical Committee ISO/TC 323, circular economy (ISO/TC 323 2021). This group of standards will include not only a set of principles and guidelines for the $\mathrm{CE}$ application, but also a measuring circularity framework. Indeed, measurement tools could be useful to improve systems (Sassanelli et al. 2019). To date, a variety of circularity indicators have been developed to tackle the lack of a harmonized methodology to assess CE strategies (Peña et al. 2021).

Albeit CE is oriented to achieve the overall sustainability, according to Helander et al. (2019), it is important to explore deeper how CE affects environmental sustainability for two main reasons: the risk of problem shifting and rebound effects which are directly linkable to environmental issues. Hence, each CE strategy should be carefully assessed because it not necessarily provides environmental benefits.

Life cycle assessment (LCA) methodology may be applied to identify the most promising circular economy strategies and options for improving the environmental performance of society's consumption and production patterns, as stated in the recent position paper by the Life Cycle Initiative (Peña et al. 2021). In Sect. 2, a focus on how circularity indicators and LCA could be used in circular decision making is presented.

\section{Focus on circularity indicators and LCA}

\subsection{Circularity indicators and their potential role in circular decision making}

Recognizing the need for a circular economy to decouple economic progress from resources depletion, the so-called circularity indicators have been developed, albeit in a disorganized way (Sassanelli et al. 2019). Research in the field of $\mathrm{CE}$ is currently evolving. Often, the metrics and indicators present contradiction in both form and content (Corona et al. 2019). Moreover, as CE is a multifaceted concept, its measurement generates different interpretations (Saidani et al. 2019). Therefore, several classifications of circularity indicators have been proposed (Elia et al. 2017; Corona et al. 2019; Sassanelli et al. 2019).

Circularity can be evaluated at different levels, i.e. at micro-, meso- or macro-level. So, circularity indicators can measure the circularity of a product or a system, i.e. the ability to conserve both the quantity and the quality of a material (Bracquené et al. 2020), or also how effective a company is in making the transition from linear to circular models. On the product level, indicators can be useful for designing new products, for internal reporting activities, or for setting procurement objectives. Instead, at company level, indicators can be used internally to compare different product ranges or to identify the progress of them. Circularity indicators can be also used externally to benchmark the circular level of more companies (Ellen MacArthur Foundation and Granta Design 2015). Indeed, by setting specific targets according to these indicators, the improvement of each company thanks to CE strategies could be monitored (Saidani et al. 2019). For the above reasons, circularity indicators offer a concrete contribute to the improvement of circular decision making. However, there are also limits in the application of such measurement tools. For example, the copious number of indicators and-in some cases - the ambiguity of their aim make difficult both the choice of which is more suitable in a specific context (Saidani et al. 2019) and a potential comparison.

The most used indicators are those referred to macrolevel evaluation, generally based on material flow analysis (MFA) (Bracquené et al. 2020). Regarding the evaluations at micro-level, the material circularity indicator (MCI) developed by Ellen MacArthur Foundation and Granta Design (2015) seems to be the most appreciated (Bracquené et al. 2020). MCI gives an indication on how much the materials which constitute a product circulate; in particular, it is able to measure the level of linear and restorative flows. Moreover, it provides information about the utility of a product (Ellen MacArthur Foundation and Granta Design 2015). However, such indicator does not fully inform about the sustainability of the product.

\subsection{LCA and its potential role in circular decision making}

LCA is a methodology developed for assessing and quantifying the potential environmental impacts associated with entire product life cycles. It is standardized in the ISO 14040 series. As previously mentioned, the Life Cycle Initiative proposed such methodology for identifying the most promising circular economy strategies. In fact, LCA can be applied to build more consistent and robust CE strategies by considering potential upstream and downstream impacts and encompassing all relevant resources and impact categories. Moreover, LCA can provide a holistic perspective into decision making, which include also both economic and social sphere, if it applied in a comprehensive way (Peña et al. 2021).

However, the LCA methodology is not perfectly able to measure the degree of circularity of the system under 
study. Two main reasons explain this limitation. First is the way LCA models raw materials and resource considerations, which often takes the linear economy as the frame of reference. LCA was in fact born to analyse the life cycle of a product from cradle to grave, i.e. from the acquisition of the raw materials to the disposal of the product after its use (Stanchev et al. 2020). Only later, rules to evaluate the impacts and benefits of reuse and recovery were developed, thus extending the study scope from cradle to cradle. However, some difficulties still exist, e.g. the lack of a consistent modelling of open recycling loops (Peña et al. 2021) as well as the lack of clear guidelines for accounting for multiple material uses with changing material qualities (Haupt and Zschokke 2017). Second, the most common characterization methods used in the LCA for the calculation of impact indicators related to the consumption of resources do not consider those in anthropogenic deposits as available (Sonderegger et al. 2020). A new approach, but still under development, is based on the concept of dissipation rather than consumption (EC-JRC 2020). Despite these limitations, the outcomes of the reviews of Corona et al. (2019) and Sassanelli et al. (2019) show that one of the most used methodology to assess CE is LCA. Corona et al. (2019) found that LCA is adopted to compare and to choose among different CE strategies. For the same authors, the holistic approach and the accumulated experience in end-of-life assessments are the main suitable characteristics of LCA in circularity measurement. LCA allows to understand and to evaluate whether the claimed environmental benefits of CE solutions can be achieved and to what extent. This methodology permits to identify also the most critical aspects of a CE strategy which need to be improved (Peña et al. 2021). Another strong point of LCA is its aim, i.e. to avoid the burden shifting. Circularity metrics are not able to do the same, because they are focused only on few goals (Corona et al. 2019) or a single activity (Helander et al. 2019).

\section{Relationship between LCA and circularity indicators}

\subsection{Conclusions of some recent studies}

Haupt and Zschokke (2017) stated that it was demonstrated that the most circular solution is not necessarily the most environmentally preferable option. Some more recent papers, where the LCA and the assessment of the circularity are carried out separately, reached the same conclusion (Table 1). For example, Lonca et al. (2018), in their analysis on the tire industry, concluded that extending lifetime through retreading and introducing recycled material improves the MCI of a tire but does not necessarily improve impacts on human health and ecosystems. Pauer et al. (2019) in their study about food packaging defined some circularity indicators to inform about material flows at the product level and the use of renewable energy. They concluded that further studies are needed to estimate how the improvement of the pro-

Table 1 Some recent studies that include both LCA evaluation and circularity assessment

\begin{tabular}{|c|c|c|}
\hline Reference & Application & Methodologies when applied separately \\
\hline Bracquené et al. 2020 & Washing machines & LCA, product circularity indicator (developed in the study) and MCI \\
\hline Glocic et al. 2020 & Alkaline batteries & LCA and MCI \\
\hline Lonca et al. 2018 & Tires & LCA and MCI (adapted) \\
\hline Pauer et al. 2019 & Food packaging & $\begin{array}{l}\text { LCA and circularity indicators (input related: recycled content, reuse rate, } \\
\text { renewable content; output related: recyclability, recycling rate, recycling } \\
\text { output rate, downcycling factor, reuse rate, compostability; energy: share of } \\
\text { renewable energy) }\end{array}$ \\
\hline Schmidt et al. 2020 & PET bottle waste management & $\begin{array}{l}\text { LCA and six material efficiency measures including the circularity potential } \\
\text { developed by Eriksen et al. (2018) }\end{array}$ \\
\hline Stanchev et al. 2020 & $\begin{array}{l}\text { Anaerobic treatment of dairy } \\
\text { processing effluents }\end{array}$ & $\begin{array}{l}\text { LCA and two new circularity metrics based on material flow analysis and LCA } \\
\text { (i.e. the Material circularity performance indicator based on the Demand } \\
\text { Minimization Index - suggested by Agudelo-Vera et al. (2012)—and the } \\
\text { Environmental circularity performance indicator based on the ratio of the } \\
\text { total environmental benefits and costs) }\end{array}$ \\
\hline Reference & Application & Methodologies when integrated \\
\hline Mantalovas and Di Mino 2020 & Asphalt mixtures & $\begin{array}{l}\text { A composite indicator of environmental sustainability and circularity assessment } \\
\text { where the environmental sustainability is quantified by LCA and circularity by } \\
\text { MCI (adapted) }\end{array}$ \\
\hline Niero and Kalbar 2019 & Beer packaging & $\begin{array}{l}\text { Two sets of indicators are coupled via a MCDA: (i) material circularity-based } \\
\text { indicators, namely material reutilization score and MCI, and (ii) a selection } \\
\text { of life cycle-based indicators relevant for beer, i.e. climate change, abiotic } \\
\text { resource depletion, acidification, particulate matter and water consumption }\end{array}$ \\
\hline
\end{tabular}


posed circularity indicators really reduces the environmental impact over the life cycle of packaging. Bracquené et al. (2020) for a case study for washing machines calculated the LCA, the MCI and a product circularity indicator (PCI) developed in the study to overcome the main limitations identified for the MCI. The authors identified some potential trade-offs and concluded that it is important to stress that the PCI only measures the circularity of the flows whereas other effects on the environment, typically assessed with a LCA, are not covered. Trade-offs were also discussed in Glocic et al. (2020), e.g. those between increasing circularity and minimizing environmental burden.

Schmidt et al. (2020) are indeed of a different opinion. In their analysis of polyethylene terephthalate (PET) bottle waste management systems in three countries, they applied LCA together with the calculation of six material efficiency indicators aiming at different stages of the waste and recycling system. They stated that a comparison between the results of the material dimension and of the environmental dimension shows that the tendency of the results in those two dimensions is similar. Stanchev et al. (2020) introduced two metrics to evaluate respectively the material and environmental circularity performance of an anaerobic digestion treatment in the dairy sector. However, in the paper, no comparison of the results obtained in the different assessments was made.

Some studies have tried to overcome this situation (i.e. in most of the cases LCA and circularity indicators give contrasting results) by considering an integration between LCA and circularity indicators (Table 1). Mantalovas and Di Mino (2020) proposed a methodology for quantifying the combined environmental sustainability and circularity of asphalt mixtures that incorporate reclaimed asphalt. The authors stated that this methodology can be used as a tool to rank different alternatives of asphalt mixtures, in terms of their environmental sustainability and circularity. They also underlined that an essential aspect of this methodology is that both types of assessment-environmental sustainability and circularity - are following identical system boundaries. This is an important consideration that enables the incorporation of both assessments' outcomes into one single indicator. Niero and Kalbar (2019) coupled different types of indicators (circularity and life cycle-based) via multi-criteria decision analysis (MCDA). Beer packaging was used as case study. The stand-alone application of the applied indicators presented a conflict and hence no alternative could have been selected. This problem of univocally identifying the best performing alternative was solved by the implementation of the MCDA.

\subsection{Discussion}

We think it is interesting to understand why some authors feel the need to use circularity indicators and if these indicators could be preferable, for some aspects, to the LCA approach.

Pauer et al. (2019) reported that in the field of their study (food packaging), producers are required to make packaging more sustainable, as this is under growing public scrutiny and regarded as a source of waste and pollution. However, they underlined a lack of a detailed guidance on how to calculate key environmental product indicators for packaging. In this context, as circularity is an increasing political and legal requirement, they identified circularity indicators as highly relevant for their assessment. Corona et al. (2019) underlined that material circularity indicators are easier to apply and to communicate to the public and to stakeholders and that, for this reason, are playing an import role in increasing the public awareness about CE. Lonca et al. (2018) highlighted that the assessment scale is a critical aspect in the identification of the type of circularity to quantify. Based on this, circularity indicators are considered essential to drive the transition to circularity at a microscale, for example, at a product or company level. At this level, according to Glocic et al. (2020), indicators are developed to incorporate circular economy ideas of resource minimization and cycling in the product design and management. To this aim, MCI can especially support a circular design to preserve the targeted materials that constitute the product.

However, most of the studies of Sect. 3.1, which apply LCA and circularity indicators separately, concluded that the results are often contrasting. This is because the circularity indicators only provide a partial view on the environmental performance of a system. Circularity metrics may be masking a burden shift towards increased energy consumption or polluting emissions (Corona et al. 2019). If the final aim is the sustainability, this implies that the choice between different alternative solutions cannot be based only on the circularity of the systems analysed.

Due to the different results in the two dimensions (i.e. circularity and environmental impacts), some authors have tried to integrate LCA and circularity indicators. The integration approach proposed by Mantalovas and Di Mino (2020) is based on a mathematical formula that includes an LCA indicator and an adapted MCI. The resulting composite indicator is considered adequate when the type of circular approach is of a closed loop type, so limiting its application. The integration of LCA and circularity indicators proposed by Niero and Kalbar (2019) is achieved through MCDA, 
coupled with a scenario-based decision making approach. In the conclusions, they suggested some improvements to the approach proposed in their study, regarding the type and number of indicators used in the analysis, the application of more than one MCDA method and the extension of the life cycle perspective to the economic and social dimension.

Either considering the results separately or integrating the circularity and environmental sustainability assessments, no authors have concluded that circularity indicators can be used alone to choose the best option in circular economy projects. The Ellen MacArthur Foundation and Granta Design (2015) itself, which developed the MCI, stated that, in the future, the MCI could be one of the parameters considered an output from an LCA or eco-design approach alongside those already typically used. At the same time, many authors expressed the need to find a common ground for practical use of environmental metrics in circularity assessment and this has been recalled by Peña et al. (2021). This request has been received through the establishment of the aforementioned ISO Technical Committee (ISO/TC 323 2021) aimed at developing guidelines and support tools for the implementation of circular economy strategies. In this context, a clear guidance could be given on how LCA and LCA-based methodologies can provide a consistent methodological basis for assessing the sustainability of $\mathrm{CE}$ solutions.

\section{Conclusions and open issues}

We can conclude that the circularity indicators, alone, are not able to assess the overall environmental performance of circular strategies. Consequently, a study based on circularity indicators must be completed by an LCA study to verify that the circularity of the system also leads to an improvement in environmental performance. Similarly, LCA studies of products or services that provide for innovations attributable to circular economy models (e.g. increase in recycled content, increase in recyclability, increase in recycling efficiency, lengthening of the use phase, increase in the possibilities of reuse of product or parts thereof) can be completed and enriched by evaluations on the circularity of the system.

However, a complete analysis-such as that offered by the combination/integration of an LCA study with the evaluation of circularity indicators-is undoubtedly complex; it requires specific skills from the side of the analyst and the use of important resources by those who request it. Furthermore, the interpretation and communication of the results could be not so straightforward. At the same time, the increase of environmental pressures and of their effects on communities and ecosystems determines the urgency to continue to improve production systems and consumption patterns; to do this in an informed and effective way, the potential of the tools described above can be exploited.

It is therefore desirable to develop a method shared by the scientific community to integrate sustainability aspects into circular economy initiatives, defining guidelines for carrying out and interpreting the results of joined studies of LCA and circularity. To this aim, we propose here a possible procedure to tackle the problem on how to integrate environmental sustainability aspects into circular economy initiatives, although at an early stage of conceptualization and open to feedbacks from the scientific community. We suggest, when different strategies are under decision, to prefer a holistic assessment of these, starting from an LCA. Later, after the exclusion of those strategies resulting with the worst impacts, the circularity analysis could be performed in support to the decision maker. Indeed, circularity cannot be totally ignored since numerous recent policies and support schemes are based on it. Moreover, as already highlighted, circularity is easier to communicate. A high degree of circularity could help to build good relationships with customers and increase reputation among stakeholders (Veleva and Bodkin 2018), as well as to have an easier access to funding, thanks to dedicated programmes (Acsinte and Verbeek 2015). At the same time, by subordinating circularity indicators to LCA, trade-offs between sustainability and circularity could be dealt with, and an acceptable level of environmental performance achievement is guaranteed.

In our opinion, this solution is less complex than including circularity indicators into LCA methodology. The addition of new indicators to the latter would make the interpretation of the results even more difficult due to the high number of indicators already included. Moreover, while a highest value in an LCA generally means a worse environmental performance and vice versa, a highest value in a circularity metric suggests a preferable strategy. This may increase the probability of mistakes in the interpretation of the results and makes their communication more difficult. For the same reason, particular attention should be paid in the weighting step (if performed), to avoid the risk of reversing the real result. A standardized procedure should be defined to guarantee a scientific validity and transparency for this type of assessment.

Acknowledgements We would like to thank Martina Bellan for her help in preparing the first draft of this article.

Funding Open access funding provided by Politecnico di Milano within the CRUI-CARE Agreement.

Open Access This article is licensed under a Creative Commons Attribution 4.0 International License, which permits use, sharing, adaptation, distribution and reproduction in any medium or format, as long as you give appropriate credit to the original author(s) and the source, provide a link to the Creative Commons licence, and indicate if changes 
were made. The images or other third party material in this article are included in the article's Creative Commons licence, unless indicated otherwise in a credit line to the material. If material is not included in the article's Creative Commons licence and your intended use is not permitted by statutory regulation or exceeds the permitted use, you will need to obtain permission directly from the copyright holder. To view a copy of this licence, visit http://creativecommons.org/licenses/by/4.0/.

\section{References}

Acsinte S, Verbeek A (2015) Assessment of access-to-finance conditions for projects supporting circular economy. Final report. https://www.eib.org/attachments/pj/access_to_finance_study_ on_circular_economy_en.pdf. Accessed 12 Aug 2021

Agudelo-Vera CM, Mels A, Keesman K, Rijnaarts H (2012) The urban harvest approach as an aid for sustainable urban resource planning. J Ind Ecol 16:839-850. https://doi.org/10.1111/j.1530-9290. 2012.00561.x

Bracquené E, Dewulf W, Duflou JR (2020) Measuring the performance of more circular complex product supply chains. Resour Conserv Recy 154:104608. https://doi.org/10.1016/j.resconrec.2019. 104608

Corona B, Shen L, Reike D, Carreón JR, Worrell E (2019) Towards sustainable development through the circular economy-a review and critical assessment on current circularity metrics. Resour Conserv Recy 151:104498. https://doi.org/10.1016/j.resconrec. 2019.104498

EC-JRC (2020) Abiotic and biotic resources impact categories in LCA: development of new approaches. Accounting for abiotic resources dissipation and biotic resources. https://ec.europa.eu/ jrc/en/publication/. Accessed 7 June 2021

Elia V, Gnoni MG, Tornese F (2017) Measuring circular economy strategies through index methods: a critical analysis. J Clean Prod 142:2741-2751. https://doi.org/10.1016/j.jclepro.2016.10.196

Ellen MacArthur Foundation (2013) Towards the Circular Economy. Vol 1. Economic and business rationale for an accelerated transition. https://www.ellenmacarthurfoundation.org/assets/downloads/publications/Ellen-MacArthur-Foundation-Towards-theCircular-Economy-vol.1.pdf. Accessed 08 Feb 2021

Ellen MacArthur Foundation and Granta Design (2015) Circularity indicators. An approach to measuring circularity. Methodology. https://www.ellenmacarthurfoundation.org/assets/downloads/ insight/Circularity-Indicators_Methodology_May2015.pdf. Accessed 9 Feb 2021

Eriksen MK, Damgaard A, Boldrin A, Astrup TF (2018) Quality assessment and circularity potential of recovery systems for household plastic waste. J Industr Ecol 23(1):156-168. https:// doi.org/10.1111/jiec. 12822

Geissdoerfer M, Savaget P, Bocken NMP, Hultink EJ (2017) The circular economy-a new sustainability paradigm? J Clean Prod 143:757-768. https://doi.org/10.1016/j.jclepro.2016.12.048

Glocic E, Young SB, Sonnemann G (2020) Confronting challenges of combining and comparing material circularity indicator with life cycle assessment indicators: a case of alkaline batteries. SETAC Europe 30th Annual Meeting - Abstract Book.

Haupt M, Zschokke M (2017) How can LCA support the circular economy?-63rd discussion forum on life cycle assessment, Zurich, Switzerland, November 30. Int J Life Cycle Assess 22(5):832837. https://doi.org/10.1007/s11367-017-1267-1

Helander H, Petit-Boix A, Leipold S, Bringezu S (2019) How to monitor environmental pressures of a circular economy. An assessment of indicators. J Industr Ecol 23:1278-1291. https://doi.org/ $10.1111 /$ jiec. 12924
ISO/TC 323 (2021) Standards by ISO/TC 323 Circular economy. https://www.iso.org/committee/7203984/x/catalogue/p/0/u/1/w/ 0/d/0. Accessed 9 Feb 2021

Kirchherr J, Reike D, Hekkert M (2017) Conceptualizing the circular economy: an analysis of 114 definitions. Resour Conserv Recy 127:221-232. https://doi.org/10.1016/j.resconrec.2017.09.005

Korhonen J, Honkasalo A, Seppälä J (2018) Circular economy: the concept and its limitations. Ecol Econ 143:37-46. https://doi.org/ 10.1016/j.ecolecon.2017.06.041

Lonca G, Muggéo R, Imbeault-Tétreault H, Bernard S, Margni M (2018) Does material circularity rhyme with environmental efficiency? Case studies on used tires. J Clean Prod 183:424-435. https://doi.org/10.1016/j.jclepro.2018.02.108

Mantalovas K, Di Mino G (2020) integrating circularity in the sustainability assessment of asphalt mixtures. Sustainability 12(2):594. https://doi.org/10.3390/su12020594

Murray A, Skene K, Haynes K (2017) The circular economy: an interdisciplinary exploration of the concept and application in a global context. J Bus Ethics 140(3):369-380. https://doi.org/10.1007/ s10551-015-2693-2

Niero M, Kalbar PP (2019) Coupling material circularity indicators and life cycle based indicators: a proposal to advance the assessment of circular economy strategies at the product level. Resour Conserv Recy 140:305-312. https://doi.org/10.1016/j.resconrec. 2018.10.002

Pauer E, Wohner B, Heinrich V, Tacker M (2019) Assessing the environmental sustainability of food packaging: an extended life cycle assessment including packaging-related food losses and waste and circularity assessment. Sustainability 11:925. https://doi.org/10. 3390/su11030925

Pearce DV, Turner RK (1990) The economics of natural resources and the environment. Harvester Wheatsheaf, Hemel Hempstead

Peña C, Civit B, Gallego-Schmid A, Druckman A, Caldeira- Pires A, Weidema B, Mieras E, Wang F, Fava J, Milà i Canals L, Cordella M, Arbuckle P, Valdivia S, Fallaha S, Motta W (2021) Using life cycle assessment to achieve a circular economy. Int J Life Cycle Assess 26:215-220. https://doi.org/10.1007/s11367-020-01856-Z

Saidani M, Yannou B, Leroy Y, Cluzel F, Kendall A (2019) A taxonomy of circular economy indicators. J Clean Prod 207:542-559. https://doi.org/10.1016/j.jclepro.2018.10.014

Sassanelli C, Rosa P, Rocca R, Terzi S (2019) Circular economy performance assessment methods: a systematic literature review. J Clean Prod 229:440-453. https://doi.org/10.1016/j.jclepro.2019.05.019

Schmidt S, Laner D, Van Eygen E, Stanisavljevic N (2020) Material efficiency to measure the environmental performance of waste management systems: a case study on PET bottle recycling in Austria, Germany and Serbia. Waste Manage 110:74-86. https:// doi.org/10.1016/j.wasman.2020.05.011

Sonderegger T, Berger M, Alvarenga R, Bach V, Cimprich A, Dewulf J, Frischknecht R, Guinée J, Helbig C, Huppertz T, Jolliet O, Motoshita M, Northey S, Rugani B, Schrijvers D, Schulze R, Sonnemann G, Valero A, Weidema BP, Young SB (2020) Mineral resources in life cycle impact assessment-part I: a critical review of existing methods. Int J Life Cycle Assess 25:784-797. https:// doi.org/10.1007/s11367-020-01736-6

Stanchev P, Vasilaki V, Egas D, Colon J, Ponsá S, Katsou E (2020) Multilevel environmental assessment of the anaerobic treatment of dairy processing effluents in the context of circular economy. J Clean Prod 261:121139. https://doi.org/10.1016/j.jclepro.2020. 121139

Veleva V, Bodkin G (2018) Corporate-entrepreneur collaborations to advance a circular economy. J Clean Prod 188:20-37. https://doi. org/10.1016/j.jclepro.2018.03.196

Publisher's Note Springer Nature remains neutral with regard to jurisdictional claims in published maps and institutional affiliations. 